After adjustment for age the partial correlation coefficients between the amount of tobacco consumed daily and the sialic acid concentrations were 0.10 $(p=0.04)$ for men and $0.01(p=0.90)$ for women (nonsmokers were assumed to consume $0 \mathrm{~g}$ ). Among men the sialic acid concentration adjusted for age was 0.69 $\mathrm{g} / \mathrm{l}$ in non-smokers and $7 \cdot 1 \mathrm{~g} / \mathrm{l}$ in smokers $(\mathrm{p}=0.09)$. The corresponding figures for women were 0.71 and $0.71 \mathrm{~g} / 1$ respectively $(\mathrm{p}=0.96)$.

There was a significant positive correlation between age and sialic acid concentration in male non-smokers and in female smokers and non-smokers. Young male smokers, however, had almost the same sialic acid concentration as old male smokers (figure). Consequently, a decreasing difference in sialic acid concentration between male smokers and non-smokers was observed with increasing age, but this trend was not significant $(p=0 \cdot 15)$.

\section{Comment}

The correlation between smoking habits and sialic acid concentration is probably low enough to rule out smoking as a confounder in the relation between sialic acid concentration and mortality from cardiovascular disease. We have already shown that sialic acid concentration increases with age in both men and women. ' In this study this trend was absent in male smokers, who from a young age had a sialic acid concentration equal to that in older male smokers. A tentative explanation for the difference found between the sexes may be that in young men smoking initiates or aggravates atherosclerosis, which increases the sialic acid concentration. In premenopausal women, who are less vulnerable to atherosclerosis this process could be less important.

1 Lindberg G, Eklund GA, Gullberg B, Răstam L. Serum sialic acid concentration and 27692 women. $B M F 1991 ; 302: 143-6$.

2 National Board of Health and Welfare. The Varmland survey. Stockholm: Allmänna Förlaget, 1971.

3 Hess EL, Coburn AF, Bates C, Murphy P. A new method for measuring sialic acid levels in serum and its application to rheumatic fever. $\mathcal{f}$ Clin Invest 1957;36:449-55.

4 Svennerholm L. Quantitative estimation of sialic acids. Biochem Biophys Acto 1957;24:604-11.

5 Carstensen J, Pershagen G, Eklund G. Mortality in relation to cigarette and pipe smoking: 16 years' observation of 25000 Swedish men. 7 Epidemiol Community Health 1987; 41:166-72.

(Accepted 4 fuly 1991)

\title{
Surveillance of antibiotic resistance in clinical isolates of Neisseria gonorrhoeae
}

\author{
C A Ison, N S Branley, K Kirtland, \\ C S F Easmon
}

\section{Department of Medical Microbiology, St Mary's Hospital Medical School, London W2 1PG \\ C A Ison, PHD, lecturer \\ N S Branley, BSC, research assistant \\ K Kirtland, FIMLs, deputy laboratory manager \\ C S F Easmon, MD, professor}

Correspondence to:

Dr Ison.

BMF 1991;303:1307

\begin{tabular}{|c|c|}
\hline \multicolumn{2}{|c|}{$\begin{array}{l}\text { In vitro susceptibility of } 896 \\
\text { consecutive gonococcal isolates to } \\
\text { ciprofloxacin and penicillin }\end{array}$} \\
\hline $\begin{array}{l}\text { Antibiotic } \\
\text { susceptibility } \\
\text { (minimum } \\
\text { inhibitory } \\
\text { concentration) } \\
\text { (mg/l) }\end{array}$ & $\begin{array}{l}\text { No }(\%) \text { of } \\
\text { isolates }\end{array}$ \\
\hline \multicolumn{2}{|l|}{ Ciprofloxacin: } \\
\hline$\leqslant 0.008$ & $840(93 \cdot 8)$ \\
\hline $0.015-0.03$ & $51(5 \cdot 7)$ \\
\hline $0 \cdot 06-0 \cdot 12$ & $2(0 \cdot 2)$ \\
\hline$>0 \cdot 12$ & $3(0 \cdot 3)$ \\
\hline \multicolumn{2}{|l|}{ Penicillin: } \\
\hline$\leqslant 0.06$ & $452(50 \cdot 4)$ \\
\hline $0 \cdot 12-0 \cdot 5$ & $379(42 \cdot 3)$ \\
\hline$\geqslant 1 \cdot 0$ & $65(7 \cdot 3)$ \\
\hline
\end{tabular}

Gonococci are becoming increasingly resistant to antimicrobial agents such as penicillin, tetracycline, the newer cephalosporins, and spectinomycin. Fluorinated quinolones such as ciprofloxacin provide an effective alternative treatment for gonorrhoea. Recent evidence of reduced gonococcal susceptibility to these agents in vitro, coupled with reports of failures of clinical treatment with quinolones, ${ }^{1}$ prompted us to determine the prevalence of reduced susceptibility to ciprofloxacin and penicillin in gonococci isolated from patients attending the sexually transmitted diseases clinic at this hospital.

\section{Materials, methods, and results}

We monitored susceptibility of 896 consecutive isolates of Neisseria gonorrhoeae to ciprofloxacin and penicillin with the agar dilution breakpoint technique. The medium used was diagnostic sensitivity agar (Oxoid) supplemented with $1 \%$ IsoVitaleX and 5\% lysed horse blood (Tissue Culture Services). The inoculum was $10^{5}$ colony forming units, and the test cultures were read after 48 hours' incubation at $36^{\circ} \mathrm{C}$ in $6 \%$ carbon dioxide. World Health Organisation control strains A-E were included in each run. Penicillin was used at concentrations of $0.06 \mathrm{mg} / \mathrm{l}$ and $0.5 \mathrm{mg} / \mathrm{l}$. Isolates that grew at both concentrations were defined as penicillin resistant (minimum inhibitory concentration $\geq 1.0 \mathrm{mg} / \mathrm{l}$ ), those that grew only at $0.06 \mathrm{mg} / \mathrm{l}$ as showing intermediate resistance (minimum inhibitory concentration $>0.06 \mathrm{mg} / \mathrm{l} \leq 0.5 \mathrm{mg} / \mathrm{l})$ and those that grew at neither concentration as penicillin sensitive (minimum inhibitory concentration $\leq 0.06 \mathrm{mg} / \mathrm{l}$ ). The categories that define reduced susceptibility to ciprofloxacin are unknown, and therefore after preliminary screening we chose three concentrations for incorpora- tion into the medium: $0.008 \mathrm{mg} / \mathrm{l}, 0.03 \mathrm{mg} / \mathrm{l}$, and 0.12 $\mathrm{mg} / \mathrm{l}$.

The table shows the in vitro susceptibility of the 896 isolates to penicillin and ciprofloxacin. The results for penicillin show the expected bimodal distribution whereas those for ciprofloxacin suggest that reduced susceptibility to the antibiotic is not yet a major problem. In only three isolates was the minimum inhibitory concentration $>0.12 \mathrm{mg} / \mathrm{l}$, in the range associated with the few reported treatment failures. ${ }^{13}$

\section{Comment}

There is as yet little information about the relation between in vitro gonococcal susceptibility to ciprofloxacin and clinical efficacy. With other Gram negative species a minimum inhibitory concentration of $1-2 \mathrm{mg} / \mathrm{l}$ is usually equated with clinical resistance. However, as such infections are usually treated with multiple dosage regimens given over several days they cannot be readily compared with gonorrhoea treated with a single dose of ciprofloxacin.

There is no evidence of plasmid mediated ciprofloxacin resistance in gonococci. Resistance probably results from either a mutation in the gene controlling DNA gyrase or a permeability barrier to ciprofloxacin in the cell envelope. ${ }^{4}$ Given the lack of knowledge about the genetic control and prevalence of reduced $\mathrm{N}$ susceptibility to ciprofloxacin in $N$ gonorrhoeae, we $\frac{D}{D}$ need to monitor the susceptibility of gonococcal isolates and hence obtain more data on the association $N$ between in vitro susceptibility and clinical efficacy. The three concentration agar incorporation breakpoint method provides a simple method of screening ciprofloxacin susceptibility patterns without the need for full testing of minimum inhibitory concentrations.

We thank Pat Woodford for technical help. The work was funded by Bayer UK.

Gransden WR, Warren C, Phillips I. 4-Quinolone-resistant Neisseria gonorrhoeae in the United Kingdom. F Med Microbiol 1991;34:23-7.

2 Gill MJ, Ison CA. Susceptibility testing of Neisseria gonorrhoeac to penicillin and spectinomycin in a diagnosic lahoratury. J Clin Pathol 1988:41:978-82. Jephcott AE, Turner A. Ciprofloxacin resistance in gonococci. Lancet 1990;335: 165

4 Lewin CS, Allen RA, Avmes SGB. Potential mechanisms of resistance to the modern fluorinated 4-quinolones. 7. Med Microbiol 1990;31:153-62.

(Accepted 17 fuly 199l) 